\title{
Tuzak nöropatilerde tedavi ilkeleri
}

\section{Treatment principles of the compression neuropathies}

\author{
Eftal Güdemez ${ }^{1}$, Serkan Uludağ ${ }^{2}$ \\ ${ }^{1}$ Koç Üniversitesi Tıp Fakültesi, Ortopedi ve Travmatoloji Bölümü, El Cerrahisi Ünitesi, İstanbul \\ ${ }^{2}$ Amerikan Hastanesi, Ortopedi ve Travmatoloji Bölümü, İstanbul
}

Elinde ağrı, uyuşma, karıncalanma, his kusuru, güç kaybı, elektriklenme ve yanma gibi şikayetleri olan hastaların tanısının doğru konulması kolay değildir. Ancak öykünün doğru alınması, iyi bir fizik muayene yapılması ve yardımcı tanı yöntemlerinden yararlanılması ile doğru tanı konulabilir. Tedavinin bu tanıya göre planlanması yetmeyebilir. Bu derlemede, sürecin baştan sona yönetilmesinin ayrıntıları, ipuçları ile birlikte verilmektedir.

Anahtar sözcükler: tuzak nöropatisi; tedavi

\section{ÖĞRENIM HEDEFLERi}

Bu makalenin sonunda okuyucu aşağıdaki konuları öğrenmiş olacaktır:

1. Tuzak nöropatisi olan bir hastayı tedavi etmek, tanıyı doğru koymaya bağlıdır.

2. Tanıyı koymada yardımcı olacak bazı önemli ayrıntıları bilmek gerekir.

3. Tedavi planını yaparken, hastanın çok iyi bilgilendirilmesi ve bunun, sözel olduğu kadar, yazılı olarak da yapılması gerekir.

4. Ameliyat da dahil olmak üzere, tedavi sürecinin baştan sona ayrıntılı olarak kayıt altına alınması çok önemlidir ve ilgili kayıt parametrelerini bilmek gerekir.

5. Tedavi her hasta için farklı olabilir; hastaya özel tedavi planının yapılması idealdir; hangi faktörlerin tedaviyi planlamada göz önünde bulundurulması gerektiği bilinmelidir.

\section{Giriş̧}

Tuzak nöropatinin doğru tedavi edilebilmesi için, öncelikle tanının doğru konulması şarttır. Doğru tanı
It is not easy to make correct diagnosis in a patient who has pain, numbness, tingling, sensory disturbances, weakness, electricity or burning symptoms in his/her hand. It is necessary to take detailed history, apply proper physical examination, and order useful diagnostic tests. However, these may not be enough to plan the treatment in such a clinical condition. In this review, the readers will find the details with practical clues for the overall management of compression neuropathies.

Key words: compression neuropathy; treatment

için; hastanın anamnezinin dikkatli bir şekilde alınması, hastaya yeteri kadar zaman ayırıp onun hakkında yeteri kadar bilgi edinilmesi, fizik muayenenin eksiksiz yapılması, nöroradyoloji ve elektrofizyolojik değerlendirmeden yardım alınması gerekir. Tanının doğru konulması da yeterli değildir. Herhangi bir tanı için tek bir tedavi reçetesi yoktur. Hastaya özel bir tedavi planı yapılmalı, bu plandan kendisine çok ayrıntılı bir şekilde bilgi verilmeli, bu 'yol arkadaşlığı' sırasında planın değişikliğe uğrayabileceği, yeterli verim alınamazsa, tedavinin olası başka seçeneklere yönlenebileceği anlatılmalıdır. Bilgi, tecrübe ve yetenek önemlidir ama karşılıklı güven, tedavinin başarısını direkt olarak etkileyecektir.

\section{ANAMNEZ VE FIZIK MUAYENEDE BIRKAÇ AYRINTI}

Hekimin, hastadan üzerini çıkarmasını istemesi önerilir. Çünkü, eski skar ve nedbeler önemli ipuçları verebilir. Hastanın söylemediği eski ameliyat veya kaza izlerini görmek çok değerli olabilir. Dirsek önündeki bir derin nedbe, median sinir dermatomundaki

- İletişim adresi: Prof. Dr. Eftal Güdemez, Koç Üniversitesi Tıp Fakültesi, Ortopedi ve Travmatoloji Bölümü, El Cerrahisi Ünitesi, İstanbul Tel: 0536 - 2198588 e-posta: gudemez.eftal@gmail.com

- Geliș tarihi: 13 Ekim $2015 \quad$ Kabul tarihi: 13 Ekim 2015 
his kusurunu açıklayabilir. Önceki travma veya benzeri bir nedenle oluşan deformiteler, hastanın şikayetleri ile örtüşebilir. Örneğin; elindeki pençeleşme, çocukluk çağında geçirdiği bir dirsek kırığına bağlı oluşmuş deformite ile direkt ilişkili olabilir. Elindeki uyuşma, güçsüzlük veya ağrı için gelen bir hastanın, omuz, kol veya önkolunda göreceğiniz atrofiler veya fasikülasyonlar, hekimin tanıyı bambaşka boyutlara götürmesini, yanlış sularda yüzmesini önleyecektir. Ya da, hastanın ilgili ekstremitesini tamamen görünür hale getirmesi, baştan ilgisiz gibi görünen yerlerindeki ele gelen kitleleri veya palpasyondaki hassas noktaları önemli hale getirecektir.

\section{Olgu 1}

Bir kadın hasta, 55 yaşında ve ev hanımı. Altı ayda yavaş yavaş ilerleyen, sol elde uyuşma ve güçsüzlük şikayeti ile geliyor. Tıbbi özgeçmişinde, özelliği olan bir durumu yok. Fizik muayenesinde, median sinir dermatomunda his kusuru ve tenar kaslarda ciddi atrofi dikkat çekiyor (Şekil 1). Bu tablo, hemen karpal tünel sendromu (KTS) tanısı üzerine yoğunlaşmanın doğru olmadığına bir örnektir ve tüm hastaların dikkatli bir şekilde değerlendirilmesi gerektiğini gerekir. Fizik muayeneye devam edince, dirsek önünde ve önkol volarinde palpasyonla, ağrı ve hassasiyet olduğu görülüyor. Pronator teres, fleksör karpi radyalis, 2. fleksör dijitorum profundus ve fleksör pollisis longus kaslarında ciddi güç kaybı olduğu tespit edilince, güçsüzlüğün sadece tenar kaslarda olmadığı anlaşılıyor. Elektrofizyolojik incelemede de, dirsek üstünden verilen median sinir uyarılarında gecikmiş distal latanslı motor yanıtlar alınınca, median sinirin dirsek üstü seviyesinde bir tuzak nöropatisi olduğu tahmin edilip, suprakondiler mahmuz veya Struthers bağı altında sıkıştığı tanısı üzerinde duruluyor. Fakat, çekilen radyografiler normal gelince, manyetik rezonans (MR) incelemesi isteniyor.

\section{Olgu 2}

Otuz beş yaşında bir kadın hasta, bir yıldır geçmeyen önkol ağrısı, elde uyuşma ve karıncalanma, güçsüzlük şikayetleri ile geliyor. Sistemik başka bir sorunu ve öyküsü olmayan bu hastanın fizik muayenesinde, median sinir duyu dermatomunda his kusuru ve tenar kaslarda güç kaybı olduğu anlaşılıyor. Önkol ağrısı üzerinde durulurken, ağrının volarde orta hatta ve proksimale doğru olduğu tespit ediliyor. Ele gelen bir patoloji olmuyor ama pronator teres, 2 . fleksör dijitorum profundus ve fleksör pollisis longus kaslarında ciddi güç kaybı olduğu görülüyor (Şekil 2). Böyle bir durumda, nadir olarak görülen tuzak nöropatilerin akla gelmesi gerekir. Pronator ve süperfisiyalis stres testlerinin (Şekil 3) yapılması ve bunların diğer ekstremite ile karşılaştırma sonuçlarının

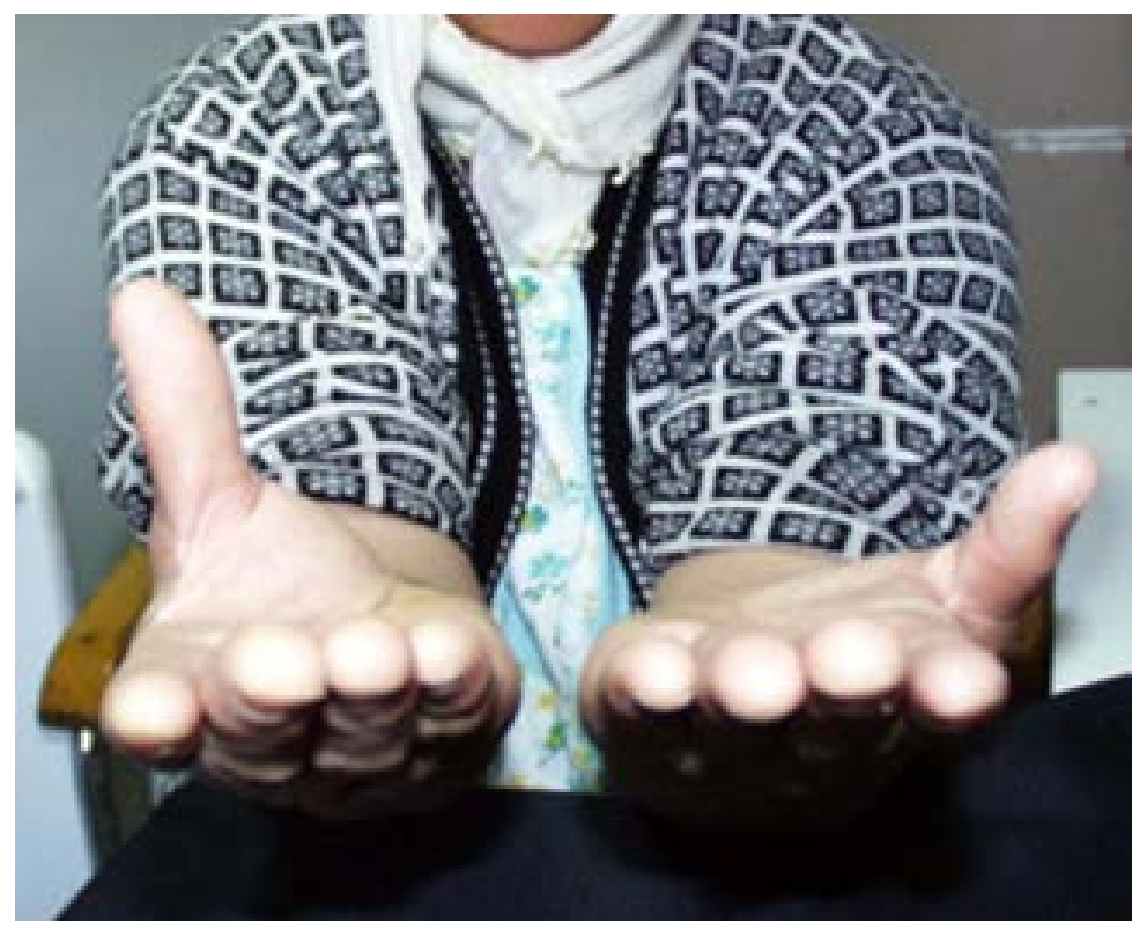

Şekil 1. Sol elde ciddi tenar atrofi görülüyor. 


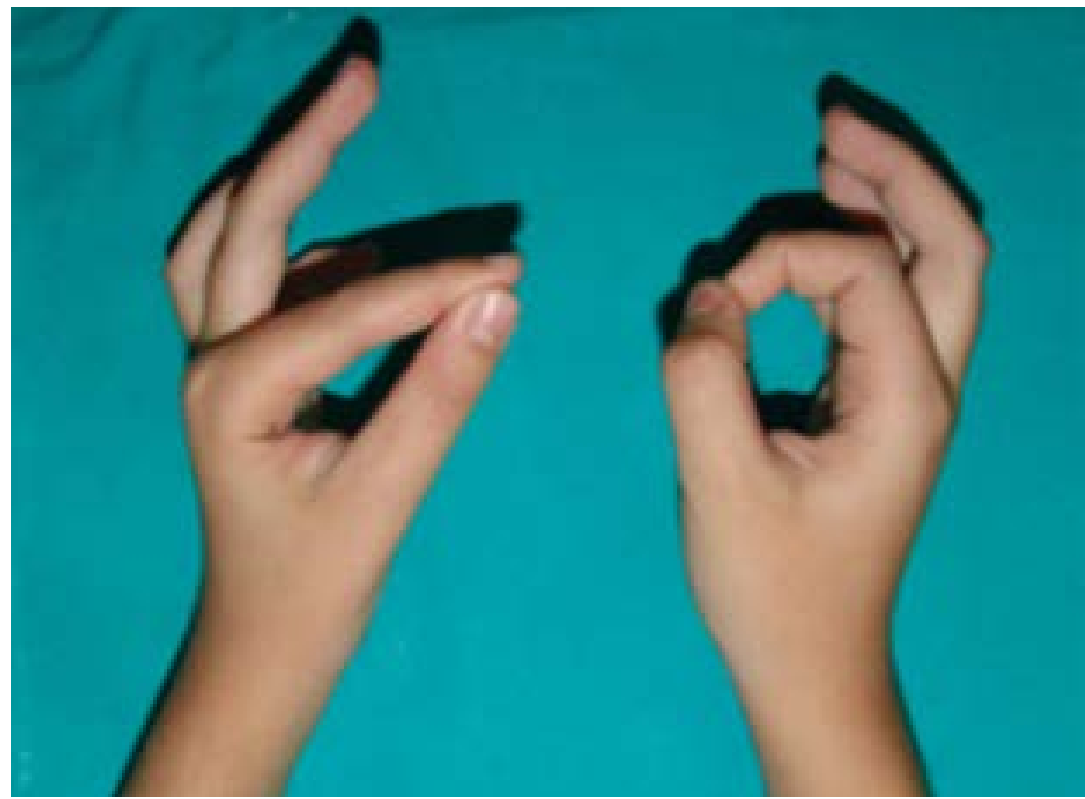

Şekil 2. İşaret parmağının fleksör dijitorum profundusunda ve fleksör pollisis longus kasında güç kaybına bağlı fleksiyon yaptıramama.

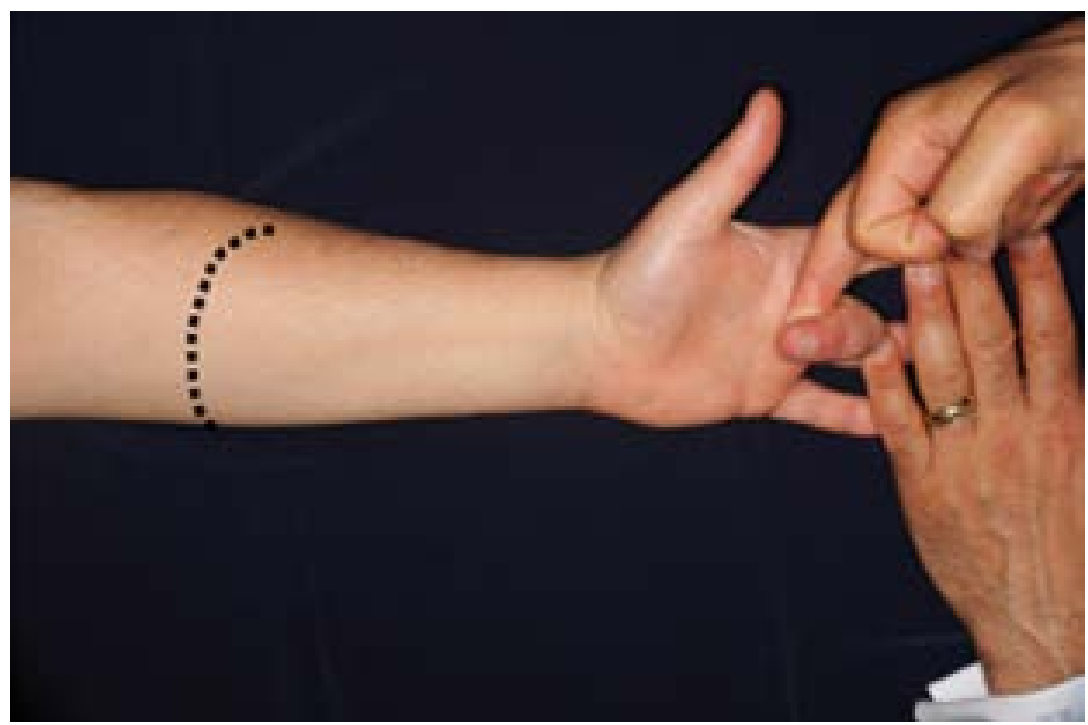

Şekil 3. Süperfisiyalis stres testinde, hastanın ağıı duyduğu lokalizasyon.

belirgin olarak pozitif bulunması, elektrofizyolojik incelemeyi yapacak olan nöroloji uzmanını yönlendirecek ve özel uygulamalar yapmasına yardımcı olacaktır.

\section{Olgu 3}

Kırk iki yaşında bir kadın hasta. Beş aydır, tüm kolda ve elde uyuşukluk tarif ediyor. Kronik bir hastalığı yok ama öyküsünde, beş ay önce gıda zehirlenmesi sonucu acil servise başvurduğunu söylüyor. Fizik muayenede, lokalize edilemeyen motor ve duyu yetmezliği var. Hafif ağrılı gevşek bir paralizi tespit ediliyor. Elektrofizyolojik incelemede yer yer odaksal demiyelinizasyon ve çoğunlukla aksonal dejenerasyon bulguları görülüyor. Bu noktada, tanıyı doğru koyabilmek için öyküyü derinleştirmek gerekiyor. Acil serviste gıda zehirlenmesi müdahalesi yapılırken, damar yolu açılması sırasında çok şiddetli ağrı oluyor ve arkasından uyuşukluk gelişiyor. Tüm üst ekstremitede iki ay boyunca süren uyuşma, ağrı ve güçsüzlükten sonra, ağrı azalıyor ama güçsüzlük ve hissizlik artıyor. Bu durum, klasik tablo dışı 
atipik durumlarda, öyküyü derinleştirmek gerekliliğine güzel bir örnek olarak değerlendirilebilir. Sadece muayene değil, öykü alma ve sorularla hastayı bu yönde ayrıntılı bilgi vermeye yönlendirmek, tanıyı, dolayısı ile tedaviyi de doğru planlamaya yardımcı olacaktır.

\section{Olgu 4}

Bu kadın hasta, 55 yaşında ve bir ofis çalışanı. Sağ kolda, sekiz aydır geçmeyen uyuşma ve ağrı şikayeti var. Konuşurken, başparmak ve işaret parmağında daha çok uyuşma olduğunu ve yukarı doğru yayıldığını ifade ediyor. Ağrısı istirahatte azalıyor. Fizik muayenesinde, başparmağı ve işaret parmakları ile önkol radyal tarafında his kusuru fark ediliyor. Tenar kaslarda ve biseps kasında güçsüzlük, C6 refleksinde azalma dikkat çekiyor. İğne elektromiyografisinde, biseps, brakiyalis ve brakiyoradyalis kas tutulumları rapor ediliyor. Duyu iletim çalışmaları normal olarak geliyor.

\section{TEDAVI PLANI, UYGULAMA, TAKIP VE KAYIT}

ilk olguda, MR incelemesi yapılınca, dirseğin hemen önünde median sinir kaynaklı bir tümör olduğu anlaşılıyor. Böyle bir muayene ve inceleme yapılmasa, hastanın rahatlıkla KTS ön tanısı ile karpal tünel dekompresyonu ameliyatına alınabileceği ve ama şikayetlerinin geçmeyeceği söylenebilir. Doğru bir tedavi planı için, tanı doğru konmalıdır. Tanı konduktan sonra, hastaya nasıl bir ameliyat gerektiği ayrıntılı bir şekilde anlatılmalıdır; ameliyat sonrası, erken-orta-uzun vadede yapılacak takip ve tedaviler hakkında bilgi verilmelidir. Beklentilerin neler olduğu, kanıtlanmış bilgiler eşliğinde açıklanmalıdır. Bu süreçte fizik tedavi ve rehabilitasyon gerekebileceği ve bunun ne kadar zaman alabileceği bilgisi verilmelidir. Tüm bu anlatılanların ve varılan mutabakatın kayıt altına alınması şarttır. Mutlaka, tuzak nöropatisi için hazırlanmış aydınlatılmış onam formları imzalatılmalı ve dosyasına konulmalıdır. Günümüz yasal süreçlerinin uluslararası pratik uygulamaları göz önüne alındığında, fizik muayene ayrıntılarının ve anlatılan bilgilerin hasta tarafından kabul edildiğinin kayıt altına alınmasının şart olduğu aşikardır. Genel prensip olarak geçerli olan kayıt altına alma yöntemleri, tuzak nöropatileri için de geçerlidir. Fizik muayene kayıtlarında, bilinen sorgulama ölçütlerinin doldurulması (disability of arm, shoulder, and hand - DASH gibi), duyu haritalarının çıkarılması (iki nokta ayrım testi ve Semmes-Weinstein monofilaman testi dahil), ekstrensik ve/veya intrensek kasların güç muayenelerinin ölçümü, dinamometre ölçümlerinin olması gerekir; bu ölçümlerin ameliyat sonrası takiplerde de yapılarak dosyasına konulması, tıbbi, etik ve yasal süreçte bizleri, avantajlı, güçlü ve donanımlı yapacaktır.
Elektrofizyolojik değerlendirmelerin, aynı bölüm, kişi ve makine tarafından yapılması, değerlendirme kalitesinin düzeyini arttıracaktır. Ameliyatın baştan sona ayrıntılı ve kaliteli bir şekilde fotoğraflanarak kayıt altına alınması, mesleki bireysel ve kurumsal arşivin donanımını güçlendirecek, hastanın ameliyattan sonra bilgilendirilmesinde yararlı olacak ve yasal süreçte istenirse gösterilmesini sağlayacaktır. Söz konusu hasta için, tüm bu süreçlerden sonra tanı konulmuş, şikayetlerin ilerleyici olması ve tümöral etiyolojiden dolayı cerrahi tedavi yoluna gidilmiştir. Schwannoma bulgusu olan tümör için (Şekil 4) mikrodisseksiyon ile fasikül koruyucu bir rezeksiyondan sonra, buna hastanın iyi bir rehabilitasyonu da eklendiğinde; hasta, orta/uzun vadede tamamen şikayetlerinden kurtulmuş, subjektif ve objektif olarak iyileştiği kayıt altına alınmıştır.

íkinci olgunun fizik muayene bulguları ve elektrofizyolojik incelemede tuzak nöropatinin lokalizasyonunun spesifik olarak dirsek distalini göstermesi, pronator teres sendromu tanısı koymamıza yardımcı oluyor. Bir yıl gibi uzun bir süredir devam etmesine ve mekanik bir kompresyon olmasına rağmen hiç bir tedavi görmemesi, konservatif tedavi yöntemlerinin planlanması ve uygulamasına engel teşkil etmemelidir. ${ }^{[1]}$ Hastaya, antiinflamatuvar tedavi, aktivite düzenlemeleri, fizik tedavi yöntemleri gibi konservatif yöntemler uygulanmış ve altı ay kadar takip edilmiştir. Bu şekilde bir takip ve izlem yapılabilir. Hasta ile ayrıntılı bir şekilde konuşulur ve sürecin başarısının takip edileceği anlatılır. Bu örnekte olduğu gibi, tüm bu yöntemlerle şikayetlerde hiç bir olumlu ilerleme sağlanamadığı durumlarda, cerrahi dekompresyon kararı verilebilir. Pronator teres sendromunda, diğer kompresyon nöropatilerinde olduğu gibi, tüm kompresyon noktaları (lasertus fibrozis altı, pronator teres kasının iki başı arası ve fleksör dijitorum süperfisiyalisin arkusunun altı) açılıp dekomprese edilmelidir. Her ameliyatta olduğu gibi, önkol dekompresyon ameliyatında da kanama kontrolü iyi yapılmalı, herhangi bir hematoma, intrakompartmantal basınç artışına neden olunmamalıdır. Sargı, bol, rahat ve hafif olmalıdır; çok iyi bir elevasyon uygulanmalı, elin ve önkolun erken aktif fonksiyonuna geçmek için gerekli meşguliyet terapisi verilmelidir. Çoğunlukla subjektif şikayetlerin ön planda olduğu söz konusu klinik tablonun, ameliyat öncesi olduğu gibi, ameliyat sonrası değerlendirme ölçüt formlarının da düzenli olarak doldurulması iyi olacaktır.

Üçüncü olgu, Parsonage-Turner sendromuna bir örnektir. Bu tanıyı koymak, hastayı anlamsız ve geri dönüşü olmayan zaman kaybından koruyacak, gereksiz ve zarar veren işlemlerin yapılmasına engel olacaktır. Tanı konulduktan sonra da, tedavinin planlanması ve yürütülmesi için bireysel davranmaktan ziyade, geniş 


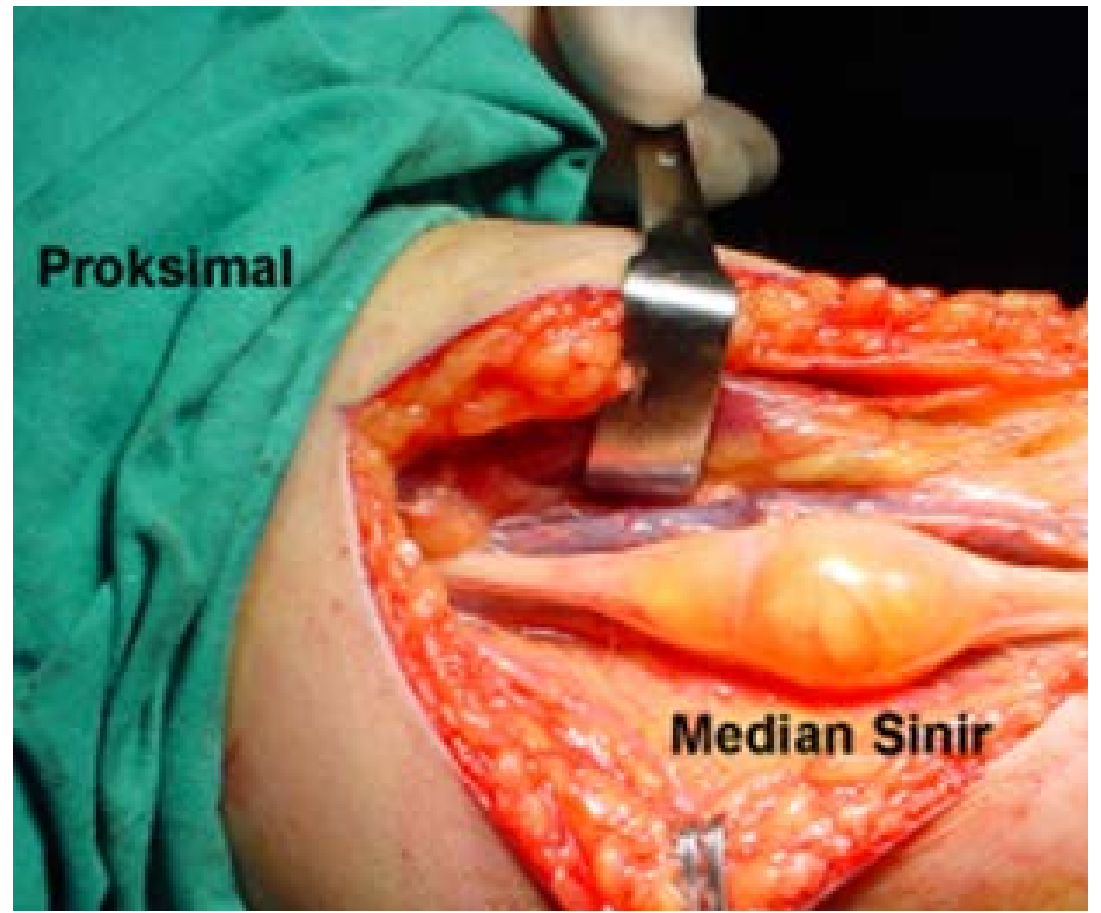

Şekil 4. Sol dirsek üstü lokalizasyonunda, makroskopik görüntüsü Schwannoma ile uyumlu median sinir tümörü.

bir ekip (ortopedi uzmanı, nöroloji uzmanı, fizik tedavi uzman hekimi ve fizyoterapisti, uğraşı terapisti gibi) çalışması yapmak gerekecektir. Rezidüel komplikasyonlar, rekürrensler ve psikolojik sorunlara gebe olan bu tür klinik durumların tedavisinin çok dikkatli yürütülmesi gerekir; kayıt, konsültasyonlar ve yeni gelişmelerin takibinin yapılmasına dikkat edilmesi önemli olacaktır. $^{[2]}$

Öykü, fizik muayene ve elektrofizyolojik çalışmaları, dördüncü olgunun açık olarak C6 radikülopati olduğunu gösteriyor. Lezyon çoğunlukla arka kök gangliyonunun daha proksimalinde olduğu için, duyusal iletim çalışmaları normal olarak kaydediliyor. Yapılacak ayrıntılı radyolojik inceleme, tedavinin nasıl yönetileceği hakkında bilgi verecektir. Fakat, bu incelemeleri hastadan bağımsız değerlendirmek her zaman doğru olmaz. Kişinin hangi ortamlarda, kaç saat, hangi pozisyonlarda çalıştığının, vücudunu ergonomik olarak nasıl kullandığının öğrenilmesinin çok büyük önemi vardır. Yanlış pozisyon alışkanlıklarının düzeltilmeye çalışılması, hem konservatif tedavide hem de ameliyat ile tedavide başarıyı arttırma ve nüksü önleme adına çok önemlidir. Kök basılarında da, tedavinin bir ekip olarak yürütülmesi iyi olur. Fizik tedavi yöntemleri veya algoloji bölümünün enjeksiyonları, hastanın şikayetlerini ciddi olarak azaltıp semptomsuz hale getirebilir.
Radikülopatilerde cerrahi tedavi kararını vermek, çok kolay olmamalıdır. Başarılı konservatif tedavi uygulamaları, hastanın tedaviye katılımı da sağlanarak mümkün olmaktadır.

Karpal tünel veya kübital tünel sendromunun proksimalde $C 6$ veya $C 7$ kök basısı gibi başka sıkışma nöropatileri ile birlikte olması, nadir görülen bir durum değildir. Double crush sendromu olarak bilinen bu klinik tabloların iyi analizi gerekir. Distalde yapılacak olan dekompresyon ameliyatlarının memnuniyet derecesinin düşük olması söz konusu olabilmektedir. O nedenle, tedavinin doğru planlanması için, kliniğin iyi anlaşılması önemli olmaktadır. Karpal tünel sendromu olan tüm hastalarda, \%41 oranında servikal artrit ve $\% 34$ diabetes mellitus tespit edilmiştir. Tüm hastalarda, \%69 oranında C6 etkilenimi bulunmuştur. Bu tip olgularda, yapılacak olan karpal tünel dekompresyonu ameliyatının başarısız olma ihtimalinin yüksek olduğu bildirilmiştir. Kübital tünel sendromlu hastalarda da, şikayetlerin bir yıldan daha uzun sürüyor olması, elektrofizyolojik incelemelerde çoklu nöropati ve radikülopatilerin tespit edilmesi, ulnar sinir dekompresyonundan önce anterior servikal diskektomi ve servikal artrodez yapılmış olmasının kübital tünel dekompresyon ameliyatının başarısını olumsuz etkilediği ispat edilmiştir. ${ }^{[3,4]}$ 


\section{SONUÇ}

Tuzak nöropatisi olan bir hastanın tedavi ilkeleri için bir reçete yoktur. Her hasta farklı özelliklere sahip olduğu için, her hastanın tedavisi de kendine özeldir. Eğer o insana göre çizilmiş bir tedavi planı ortaya konmaz ve herkese aynı tedavi ilkeleri uygulanırsa, başarısız olma ihtimali artar. Hasta memnuniyetsizliği, bizlere, manevi, etik ve legal olarak olumsuz yansıyacaktır.

\section{KAYNAKLAR}

1. Olehnik WK, Manske PR, Szersinski J. Median nerve compression in the proximal forearm. J Hand Surg Am 1994;19(1):121-6.

2. Feinberg $\mathrm{JH}$, Radecki J. Parsonage-turner syndrome. HSS J 2010;6(2):199-205. CrossRef

3. Hurst LC, Weissberg D, Carroll RE. The relationship of the double crush to carpal tunnel syndrome (an analysis of 1,000 cases of carpal tunnel syndrome). J Hand Surg $\mathrm{Br}$ 1985;10(2):202-4.

4. Galarza M, Gazzeri R, Gazzero G, Gazzeri G, Zuccarello $M$, Taha J. Cubital tunnel surgery in patients with cervical radiculopathy: double crush syndrome? Neurosurg Rev 2009;32(4):471-8. CrossRef 